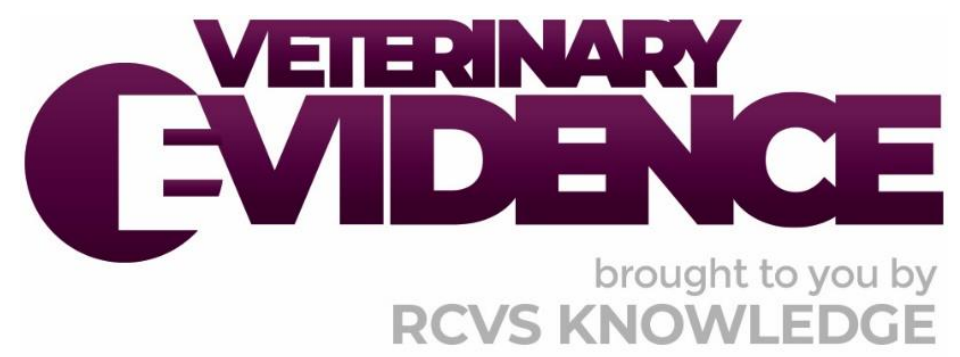

\title{
Distal tarsal joints osteoarthritis: Evidence behind bisphosphonates and NSAIDs to improve lameness
}

A Knowledge Summary by

Julia Dubuc DMV, DÉS, DACVS-LA, M.Sc, MRCVS ${ }^{1^{*}}$

\footnotetext{
${ }^{1}$ University of Nottingham, Sutton Bonnington Campus, Sutton Bonnington, Leicestershire, LE12 5RD

*Corresponding Author (julia.dubuc@nottingham.ac.uk)
}

ISSN: 2396-9776

Published: 28 Feb 2020

in: Vol 5, Issue 1

DOI: 10.18849/VE.V5I1.204

Reviewed by: Michael Schoonover (DVM, MS, DACVS-LA, DACVSMR) and Elisabeth Swann (BSc, PGCert, MA)

Next Review Date: Jul 25th 2020 


\section{KNOWLEDGE SUMMARY}

\section{PICO question}

In lame horses affected by osteoarthritis of the distal tarsal joints (bone spavin), are bisphosphonates more effective than NSAIDs in long-term alleviation of lameness?

\section{Clinical bottom line}

\section{Category of research question}

Treatment

\section{The number and type of study designs reviewed}

Two papers were critically reviewed. There was one field study and a multicentric randomised double-blind placebo control study

\section{Strength of evidence}

Weak

\section{Outcomes reported}

Each study looked at the effect of either Tiludronate or Firocoxib on alleviation of tarsal lameness. Both Tiludronate and Firocoxib, while administered independently, provided some degree of relief (for up to 120 days) and improved the lameness related to tarsal osteoarthritis

\section{Conclusion}

Since no study was found to directly compare the use of non-steroidal anti-inflammatory drugs and bisphosphonates and that none evaluate the long-term effects of these treatment options on lameness, it is not possible to recommend one treatment option over the other to alleviate lameness caused by tarsal osteoarthritis in horses

\section{How to apply this evidence in practice}

The application of evidence into practice should take into account multiple factors, not limited to: individual clinical expertise, patient's circumstances and owners' values, country, location or clinic where you work, the individual case in front of you, the availability of therapies and resources.

Knowledge Summaries are a resource to help reinforce or inform decision making. They do not override the responsibility or judgement of the practitioner to do what is best for the animal in their care.

\section{Clinical Scenario}

You are presented with an 18-year-old retired 3 star eventer, predominantly used now for low level work in the manège. The owner reports the horse lacks impulsion prior to jumping and that he now engages both hindlimbs much less under saddle. On lameness exam, no proper lameness is observed, but the full flexion of both hindlimbs is clearly positive. You elect to perform bilateral tarsal radiographs, which highlight periarticular osteophytes over the dorsomedial aspect of both the distal intertarsal and tarsometatarsal joints. On the dorsoplantar view, some lysis of these joint spaces is observed and is surrounded by sclerosis. You diagnose the horse with bilateral osteoarthritis (OA) of the distal tarsal joints. 


\section{The evidence}

Only two relevant studies were identified, one of which is a field study with no mandatory radiographs required to enter the study, indicating the horses included were not necessarily diagnosed with distal tarsal joints OA. The second study is a randomised double-blind placebo control study, but it was not entirely blinded. The level of evidence of the studies summarised below is low regarding the use of bisphosphonates as a treatment for distal tarsal joint OA. There is a more substantial body of literature focusing on the use of bisphosphonates as a treatment of navicular syndrome in horses. There is no study in the literature providing a direct comparison of non-steroidal anti-inflammatory drugs (NSAIDs) and bisphosphonates for the longterm alleviation of lameness related to distal tarsal joints $O A$ and for navicular syndrome.

\section{Summary of the evidence}

\begin{tabular}{|c|c|}
\hline \multicolumn{2}{|l|}{ Orsini et al. (2012) } \\
\hline Population: & $\begin{array}{l}\text { Horses from } 25 \text { states in the USA. } \\
\text { Age: mean } 13.3 \text { years old (yo) (range } 18 \text { months-32 yo) } \\
\text { Breeds: } \\
\text { - Quarter Horse (QH) and Thoroughbred (TB) = > } 50 \% \text { of } \\
\text { population } \\
\text { - Others: Standardbred (Stb), Appaloosa, Tennessee Walking } \\
\text { Horse, crossbreeds } \\
\text { Inclusion criteria: } \\
\text { 1. > } 1 \text { yo } \\
\text { 2. Lameness and signs of pain attributed to OA } \\
\text { 3. Lameness at least moderate (Grades } 2-4 / 5 \text { American } \\
\text { 4. Association of Equine Practitioners (AAEP) Lameness Scale) } \\
\text { 4. Lameness duration of at least } 4 \text { weeks }\end{array}$ \\
\hline Sample size: & $\begin{array}{l}\text { Initial } n=467 \text { enrolled } \\
\text { Final } n=390 \text { were included for analyses }\end{array}$ \\
\hline Intervention details: & $\begin{array}{l}\text { For each horse: } \\
\text { - Firocoxib paste, } 0.1 \mathrm{mg} / \mathrm{kg} \text {, per os (PO), once a day (SID) for } \\
14 \text { consecutive days (day } 1 \text { to } 14 \text { included). } \\
\text { - Three scheduled examinations (including lameness) by } \\
\text { attending veterinarian: } \\
\circ \quad \text { Day } 0 \\
\circ \quad \text { Day } 7 \\
\circ \quad \text { Day } 14 \\
\text { - Caregivers daily interpretation of the horse's lameness } \\
\text { status (as well as palatability and convenience of } \\
\text { administration) was recorded on a lameness form (for each } \\
\text { of the } 14 \text { days) }\end{array}$ \\
\hline Study design: & Field study \\
\hline Outcome studied: & $\begin{array}{l}\text { Subjective assessment of the lameness by a veterinarian on day } 7 \\
\text { and } 14 \text {, using the AAEP Lameness Scale scoring guide }\end{array}$ \\
\hline $\begin{array}{l}\text { Main findings: } \\
\text { (relevant to PICO question): }\end{array}$ & $\begin{array}{l}\text { Initial diagnosis of OA: } \\
\qquad \begin{array}{rl}\text { - } & \text { Lameness at day } 0 \text { (starting lameness): } \\
\circ & 155 / 390(39.7 \%) \text { had grade } 2 / 5 \text { lameness } \\
0 & 160 / 390(41 \%) \text { had grade } 3 / 5 \text { lameness }\end{array}\end{array}$ \\
\hline
\end{tabular}




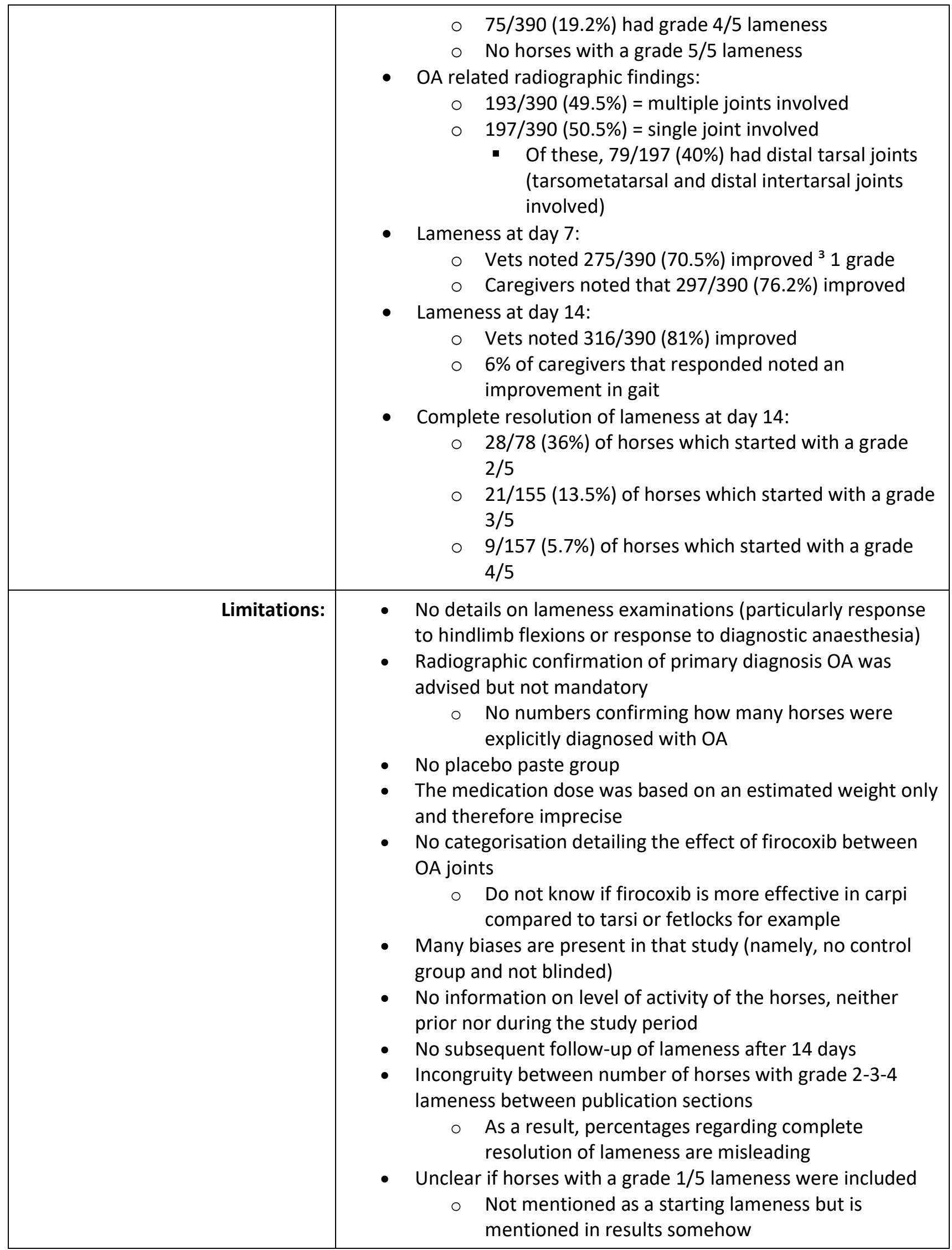




\begin{tabular}{|c|c|}
\hline \multicolumn{2}{|l|}{ Gough et al. (2010) } \\
\hline Population: & $\begin{array}{l}\text { Adult horses from } 13 \text { centres and multiple countries } \\
\text { Age: mean } 11 \text { yo (range } 5-20 \text { yo) } \\
\text { Weight: mean } 540.2 \mathrm{~kg} \text { (range } 304-748) \\
\text { Inclusion criteria: } \\
\text { 1. } 6 \text { weeks to } 1 \text { year spontaneous lameness } \\
\text { 2. Horses with walking }+^{3} 30 \text { minute of trot per day } \\
\text { 3. Lameness score of lamest limb }{ }^{3} 3 \text { after intra-articular (IA) } \\
\text { analgesia of tarsometatarsal or centrodistal joints } \\
\text { 4. Positive intra-articular IA analgesia ( }{ }^{3} 50 \% \text { improvement) for } \\
\text { centrodistal or tarsometatarsal joints } \\
\text { 5. Radiographic signs of OA on } 1 \text { or more of the } 4 \text { standard } \\
\text { tarsal views of lamest hindlimb: joint space narrowing, lytic } \\
\text { lesions, sclerosis, thickening of subchondral bone and new } \\
\text { bone proliferation }\end{array}$ \\
\hline Sample size: & $\begin{array}{l}\text { Initial } n=108 \text { enrolled } \\
\text { Final } n=87 \text { were included for analyses }\end{array}$ \\
\hline Intervention details: & $\begin{array}{l}\text { - Horses divided in to two groups: } \\
\text { 1. Tiludronate (T), } \mathrm{n}=42,1 \mathrm{mg} / \mathrm{kg} \\
\text { 2. Placebo (P), } \mathrm{n}=45 \\
\text { - Treatment/Placebo administered intravenously (IV) in } 1 \mathrm{~L} \text { bag } \\
\text { of saline over } 30 \text { minutes } \\
\text { - Three scheduled examination by veterinarian: } \\
\quad \text { Day 0 } \\
\quad \text { Day 60: IA analgesia of least lame limb repeated + } \\
\text { scoring of lamest limb* } \\
\quad \text { Day 120: IA analgesia of least lame limb repeated + } \\
\quad \text { scoring of lamest limb* } \\
\quad \text { *If lamer than before, distal tarsal IA block repeated } \\
\quad+\text { tarsus radiographs } \\
\text { - NSAIDs use was allowed for lameness or other concurrent } \\
\text { disease, but a } 15 \text { day wash out period was mandatory prior } \\
\text { to next examination by the veterinarian } \\
\text { No rest during the study period as owners were advised to } \\
\text { gradually increase their horses' level of exercise }\end{array}$ \\
\hline Study design: & $\begin{array}{l}\text { Randomised double-blind placebo control study } \\
\text { Multicentric (13 centers) and multinational }\end{array}$ \\
\hline Outcome studied: & $\begin{array}{c}\text { - Lameness scores at day } 60 \text { and } 120 \text { compared to day } 0 \\
\circ \quad 0-10 \text { Wyn-Jones lameness grading scale }\end{array}$ \\
\hline $\begin{array}{l}\text { Main findings: } \\
\text { (relevant to PICO question): }\end{array}$ & $\begin{array}{l}\text { - Significant treatment effect in favour of Tiludronate } \\
\text { - The higher the lameness score at day } 0 \text {, the higher the score } \\
\text { at day } 60 \text { (covariate baseline significant) } \\
\text { - At day } 60 \text {, lameness scores of group } T<P \\
\quad 0 \text { Group T: } 4.5 \pm 1 \text { (day } 0 \text { ) vs } 2.6 \pm 1.7 \text { (day } 60 \text { ) } \\
\quad \text { Group P: } 4.5 \pm 0 \text { (day } 0 \text { ) vs } 3.3 \pm 2.0 \text { (day } 60 \text { ) } \\
\text { - At day } 60 \text {, no difference in lameness between groups } \\
\text { associated to NSAIDs use } \\
\text { - At day } 120 \text {, significant improvement in lameness for group T }\end{array}$ \\
\hline
\end{tabular}




\begin{tabular}{|c|c|}
\hline & $\begin{array}{l}\text { - In horses with peri-articular osteophytes, mean lameness } \\
\text { score was lower in group T vs P } \\
\text { - Significant difference in mean body weight between groups } \\
\text { o (Tiludronate: } 521 \mathrm{~kg} \text {; Placebo: } 568 \mathrm{~kg} \text { ) }\end{array}$ \\
\hline Limitations: & $\begin{array}{l}\text { - No subsequent follow-up of lameness after } 4 \text { months } \\
\text { - Lameness evaluations are extremely subjective and was } \\
\text { evaluated by multiple different individuals } \\
\text { - Use of NSAIDs was permitted during the clinical trial } \\
\text { - Not a fully double-blind placebo control study } \\
\text { At day } 60 \text {, horses with inadequate response could } \\
\text { be treated with tiludronate } \\
\text { - Unclear if this includes placebo only cases or if } \\
\text { tiludronate horses had a second dose then } \\
\text { - No exercise protocol established for the study period and } \\
\text { left at the attending clinicians discretion } \\
\text { Despite this, statistical analyses and conclusions are } \\
\text { drawn about improvement of exercise during the } \\
\text { study } \\
\text { - No objective measure of tiludronate effect: } \\
\text { Unclear if tarsal radiographs were repeated at day } \\
60 / 120 \\
\text { No subsequent follow-up of lameness after } 4 \text { months }\end{array}$ \\
\hline
\end{tabular}

\section{Appraisal, application and reflection}

There is no prospective clinical study comparing the effects of NSAIDs versus bisphosphonates on improvement of lameness related to bone spavin in horses. There are two generations of biosphosphonates. The early generation, contains nitrogen and includes tiludronate and clodronate, which are considered less potent. The latest generation comprises pamidronate and zoledronate and are highly potent.

There are more publications looking into bisphosphonates as a treatment for navicular disease (Denoix, J. M. et al., 2003; Dyson, S. J. et al., 2005; Mitchell, A. et al., 2019; and Whitfield, C.T. et al., 2016), but the work of Gough et al. (2010) appears to be the only publication found by the author on the use of bisphosphonates as a treatment for bone spavin in horses. A review of the efficacy of tiludronate in horses (Kamm, L. et al., 2008) mentions several smaller studies, namely a case series (Riccio, B. et al., 2002) and clinical observations (Dyson, S. J. et al., 2004) that were never officially published. None of these provide sufficient evidence that bisphosphonates are truly beneficial in cases of distal tarsal joints OA.

In both of the publications presented here, lameness is used as the principal outcome evaluated to determine if either firocoxib or tiludronate are effective in improving the lameness of the horses with distal tarsal joints OA. As lameness evaluation is a very subjective process and taken together with the fact both studies are "multicentric", the accuracy of the outcome evaluation is questionable. Unlike more recent studies on the topic (Mitchell, A. et al. 2019 and Whitfield, C.T. et al. 2016), no inertial sensor system nor ground-mounted stationary force plate system was employed. Further publications with more objective lameness evaluations and other measured outcomes are needed. For example, in a similar study comparing the efficacy of phenylbutazone versus firocoxib in horses with naturally occurring osteoarthritis (Doucet, $M$. Y. et al., 2008), lameness was used as the outcome evaluated, as well as other more objective measures: reaction to manipulation/joint flexion, joint swelling, joint circumference and range of motion.

In the study by Orsini et al. (2012), the lamenesses were graded on the AAEP Lameness Scale (Grade 0-5) by a veterinary surgeon on days 0,7 and 14, but were also graded by the horses' caregivers on days 7 and 14 . As there was no placebo or control group in this study, none of these individuals were blinded and all were aware the horse was under treatment with firocoxib. In the study by Gough et al. (2010), the lameness was 
graded on a scale of $0-10$ by a veterinary surgeon on days 0,60 and 120 in a randomised double-blind placebo control study. However, the authors state that horses not responsive to treatment at day 60 could receive the standard dose of tiludronate at that time, voiding the double-blind aspect of the study design. These breaches in study designs introduce biases, namely in the assessment of the lameness and this greatly impacts on the reliability of the results.

Interestingly, the author only found the study from Orsini et al. (2012) looking at firocoxib as an NSAID medication for distal tarsal joints OA and "none" using phenylbutazone. The study from Orsini et al. (2012) is in fact a clinical trial investigating the efficacy of firocoxib in management of musculoskeletal pain and lameness associated with osteoarthritis. While 197/390 (50.5\%) of the horses had signs of musculoskeletal pain or lameness associated with one joint, 79/197 (40.1\%) of these were thought to involve the tarsus (radiographs were not mandatory to confirm the diagnosis). The results are presented in such a way that it is not possible to determine how many of these horses affected with tarsal OA really improved because of firocoxib administration. The authors report $80 \%$ improvement of lameness overall after 14 days. In a very similar study (Doucet, M. Y. et al., 2008), published prior to the above mentioned, there was no difference in lameness scores between the firocoxib group $(0.1 \mathrm{mg} / \mathrm{kg}$, PO, SID for 14 days) and the phenylbutazone group ( $4.4 \mathrm{mg} / \mathrm{kg}, \mathrm{PO}, \mathrm{SID}$ for 14 days) for pain related to naturally occurring osteoarthritis (which was confirmed radiographically prior to entering the study). In the latter as in the former, there is no clear groups separating the effect of each NSAIDs on horses affected by tarsal OA compared to any other degenerative joint disease. However, the author chose not to present the work of Doucet here as all horses fell under one large category: naturally occurring $O A$.

Based on the current literature, there is insufficient evidence to advocate for the use of NSAIDs more than bisphosphonates or the contrary for the treatment of distal tarsal joints OA in horses. The longest follow-up period was 4 months in the study from Gough et al. (2010) and 2 weeks for Orsini et al. (2012). There is a need for a prospective double-blind clinical trial including one bisphosphonates group, one NSAID group and one control group with long-term follow-up of the horses lameness as well as other more objective outcomes.

For an overview of the efficacy and effects of bisphosphonates in horses with navicular disease, the reader can consult recent publications, including different administration routes: IM (Mitchell, A. et al. 2019), IV or intravenous regional limb perfusion (IV-RLP) (Whitfield, C.T. et al. 2016; Schoonover, M.J. et al. 2019).

\section{Methodology Section}

\begin{tabular}{|c|c|}
\hline $\begin{array}{r}\text { Databases searched and dates } \\
\text { covered: }\end{array}$ & $\begin{array}{l}\text { CAB Abstracts } 1973 \text { to Week } 282018 \\
\text { PubMed NCBI } 1910 \text { to Week } 282018\end{array}$ \\
\hline Search terms: & $\begin{array}{l}\text { CAB Abstracts } \\
\text { 1. equine or equines or horse or horses or equus or equid or } \\
\text { equids or mare or mares or broodmare or broodmares or } \\
\text { pony or ponies or filly or fillies or colt or colts or yearling or } \\
\text { yearlings or stallion or stallions or thoroughbred or } \\
\text { thoroughbreds or standardbred or standardbreds or } \\
\text { racehorse or racehorses or "race horse" or "race horses" or } \\
\text { exp horses/ or exp equus/ or exp equidae/ or exp mares/ or } \\
\text { exp colts/ or exp foals/ or exp stallions/ or exp } \\
\text { thoroughbred/ or exp racehorses/ } \\
\text { 2. arthritis or arthritic or arthritogenic or arthritical or } \\
\text { osteoarthritis or osteoarthritic or osteo-arthritis or osteo- } \\
\text { arthritic or synovitis or "joint disease" or "joint diseases" or } \\
\text { OA or DJD or osteoarthrosis or osteo-arthrosis or lame or }\end{array}$ \\
\hline
\end{tabular}


lameness or spavin or gait or exp osteoarthritis/ or exp

arthritis/ or exp joint diseases/

3. tarsal or tarsals or tarsale or tarsometatarsal or tarsometatarsus or tarsometatarsals or tarso-metatarsal or tarso-metatarsals or carpus or carpuses or carpometacarpal or carpometacarpals or carpo-metacarpal or carpometacarpals or hock or hocks or carpal or carpals or exp tarsus/ or exp carpus/

4. bisphosphonate or bisphosphonates or biphosphonate or biphosphonates or bisphosponate or bisphosponates or biphosponate or biphosponates or disphosponate or disphosponates or diphosphonate or diphosphonates or diphosponate or diphosponates or disphosphonate or disphosphonates or osphosReg or tiludronate or tiludronic or tildren or tildrenReg or clodronate or clodronic

5. NSAID or NSAIDs or "non steroidal anti inflammatory" or "non steroidal anti inflammatories" or "non steroidal antiinflammatory" or "non steroidal antiinflammatories" or "nonsteroidal anti inflammatory" or "nonsteroidal anti inflammatories" or "nonsteroidal antiinflammatory" or "nonsteroidal antiinflammatories" or phenylbutazone or phenylbutazones or PBZ or firocoxib or firocoxibs or FIRO or cox-2-selectives or cox-2-selective or exp antiinflammatory agents/ or exp non-steroidal antiinflammatory agents/

6. 1 and 2 and 3 and ( 4 or 5 )

PubMed

1. equine or equines or horse or horses or equus or equid or equids or mare or mares or broodmare or broodmares or pony or ponies or filly or fillies or colt or colts or yearling or yearlings or stallion or stallions or thoroughbred or thoroughbreds or standardbred or standardbreds or racehorse or raceshorses

2. arthritis or arthritic or arthritogenic or arthritical or osteoarthritis or osteoarthritic or osteo-arthritis or osteoarthritic or synovitis or "joint disease" or "joint diseases" or OA or DJD or osteoarthrosis or osteo-arthrosis or lame or lameness or spavin or gait

3. tarsal or tarsals or tarsale or tarsometatarsal or tarsometatarsus or tarsometatarsals or tarso-metatarsal or tarso-metatarsals or carpus or carpuses or carpometacarpal or carpometacarpals or carpo-metacarpal or carpometacarpals or hock or hocks or carpal or carpals

4. bisphosphonate or bisphosphonates or biphosphonate or biphosphonates or bisphosponate or bisphosponates or biphosponate or biphosponates or disphosponate or disphosponates or diphosphonate or diphosphonates or diphosponate or diphosponates or disphosphonate or disphosphonates or osphosReg or tiludronate or tiludronic or tildren or tildrenReg or clodronate or clodronic

5. NSAID or NSAIDs or "non steroidal anti inflammatory" or "non steroidal anti inflammatories" or "non steroidal 


\begin{tabular}{|l|l|}
\hline & $\begin{array}{l}\text { antiinflammatory" or "non steroidal antiinflammatories" or } \\
\text { "nonsteroidal anti inflammatory" or "nonsteroidal anti } \\
\text { inflammatories" or "nonsteroidal antiinflammatory" or } \\
\text { "nonsteroidal antiinflammatories" or phenylbutazone or } \\
\text { phenylbutazones or PBZ or firocoxib or firocoxibs or FIRO or } \\
\text { cox-2-selectives or cox-2-selective } \\
\end{array}$ \\
\hline Dates searches performed: 1 and 2 and 3 and (4 or 5)
\end{tabular}

\begin{tabular}{|c|c|}
\hline \multicolumn{2}{|l|}{ Exclusion / Inclusion Criteria } \\
\hline Exclusion: & $\begin{array}{l}\text { - Articles not relevant to PICO question } \\
\circ \quad \text { Carpal joints } \\
\circ \quad \text { Induced arthritis } \\
\circ \quad \text { Ex vivo research } \\
\text { - Conference papers/proceedings not published/review paper } \\
\text { - Publications in other languages than French or English }\end{array}$ \\
\hline Inclusion: & $\begin{array}{l}\text { - Relevant to PICO question } \\
\quad \text { Tarsal joints/hocks OA } \\
\circ \text { Bisphosphonates/Tildren/tiludronate/clodronate/ } \\
\circ \text { NSAIDs }\end{array}$ \\
\hline
\end{tabular}

\begin{tabular}{|c|c|c|c|c|c|c|}
\hline \multicolumn{7}{|c|}{ Search Outcome } \\
\hline Database & $\begin{array}{c}\text { Number } \\
\text { of } \\
\text { results }\end{array}$ & $\begin{array}{l}\text { Excluded - } \\
\text { other } \\
\text { languages }\end{array}$ & $\begin{array}{l}\text { Excluded - Not } \\
\text { relevant to } \\
\text { PICO }\end{array}$ & $\begin{array}{l}\text { Excluded - } \\
\text { duplicates }\end{array}$ & $\begin{array}{c}\text { Excluded - } \\
\text { conference } \\
\text { papers or } \\
\text { proceedings } \\
\text { not published, } \\
\text { book chapters }\end{array}$ & $\begin{array}{c}\text { Total } \\
\text { relevant } \\
\text { papers }\end{array}$ \\
\hline $\begin{array}{l}\text { CAB } \\
\text { abstracts }\end{array}$ & 72 & 10 & 50 & 0 & 10 & 2 \\
\hline PubMed & 45 & 1 & 23 & 21 & 0 & 0 \\
\hline \multicolumn{6}{|c|}{ Total relevant papers } & 2 \\
\hline
\end{tabular}


The author declares no conflict of interest.

\section{REFERENCES}

1. Denoix, J.M., Thibaud, D. \& Riccio, B. Tiludronate as a new therapeutic agent in the treatment of navicular disease: a double-blind placebo-controlled clinical trial. Equine Veterinary Journal. 2003; 35(4): 407-13. DOI: https://doi.org/10.2746/042516403776014226

2. Dyson, S. Are There any Advances in the Treatment of Distal Hock Joint Pain? Proceedings International Symposium on Diseases of the Icelandic Horse, 2004.

3. Dyson S.J., Murray R. \& Schramme M.C. Lameness associated wth foot pain: results of magnetic resonance imaging in 199 horses (January 2001-December 2003) and response to treatment. Equine Veterinary Journal. 2005; 37: 113-121. DOI: https://doi.org/10.2746/0425164054223804

4. Gough, M.R., Thibaud, D. \& Smith, R.K. Tiludronate infusion in the treatment of bone spavin: a double blind placebo-controlled trial. Equine Veterinary Journal. 2010; 42(5): 381-7.

DOI: https://doi.org/10.1111/j.2042-3306.2010.00120.x

5. Kamm, L., Mcllwraith, W. \& Kawcak, C. A review of the efficacy of tiludronate in the horse. Journal of Equine Veterinary Science. 2008; 28(4): 209-14. DOI: https://doi.org/10.1016/i.jevs.2008.02.007

6. Riccio, B., Thibaud, D. \& Denoix, J.M. A double-blind placebo-controlled trial of tiludronate in the treatment of bone spavin. BEVA Congress; 2002.

7. Doucet, M.Y., Bertone, A.L., Hendrickson, D., Hughes, F., Macallister, C., McClure, S., Reinemeyer, C., Rossier, Y., Sifferman, R., Vrins, Andre A., White, G., Kunkle, B., Alva, R., Romano, D. \& Hanson, P.D. Comparison of efficacy and safety of paste formulations of firocoxib and phenylbutazone in horses with naturally occurring osteoarthritis. Journal of the American Veterinary Medical Association. 2008; 232(1): 91-7. DOI: https://doi.org/10.2460/javma.232.1.91

8. Orsini, J.A., Ryan, W.G., Carithers, D.S. \& Boston, R.C. Evaluation of oral administration of firocoxib for the management of musculoskeletal pain and lameness associated with osteoarthritis in horses. American Journal of Veterinary Research. 2012; 73(5): 664-71.

DOI: https://doi.org/10.2460/ajvr.73.5.664

9. Mitchell, A., Wright, G., Sampson, S.N., Martin, M., Cummings, K., Gaddy, D. \& Watts, A.E. Clodronate improves lameness in horses without changing bone turnover markers. Equine Veterinary Journal. 2019; 51: 356-63. DOI: https://doi.org/10.1111/evj.13011

10. Whitield, C.T., Schoonover, M.J., Holbrook, T.C., Payton, M.E. \& Sippel, K.M. Quantitative assessment of two methods of tiludronate administration for the treatment of lameness caused by navicular syndrome in horses. American Journal of Veterinary Research. 2016; 77(2): 167-73.

DOI: https://doi.org/10.2460/ajvr.77.2.167 
11. Schoonover, M.J., Whitield, C.T., Young, J.M., Sippel, K.M. \& Payton, M.E. Quantitative assessment of intravenous regional limb perfusion of tiludronate as an adjunctive treatment for lameness caused by navicular syndrome in horses. American Journal of Veterinary Research. 2018; 79(12): 1313-1320. DOI: https://doi.org/10.2460/ajvr.79.12.1313

Acknowledgement

RCVS Knowledge was supported in producing this Knowledge Summary by an educational grant from Petplan Charitable Trust. 


\section{EVIIDEFeE

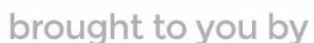 \\ RCVS KNOWLEDGE}

\section{Intellectual Property Rights}

Authors of Knowledge Summaries submitted to RCVS Knowledge for publication will retain copyright in their work, and will be required to grant RCVS Knowledge a non-exclusive license of the rights of copyright in the materials including but not limited to the right to publish, re-

publish, transmit, sell, distribute and otherwise use the materials in all languages and all media throughout the world, and to license or permit others to do so.

\section{Disclaimer}

Knowledge Summaries are a peer-reviewed article type which aims to answer a clinical question based on the best available current evidence. It does not override the responsibility

of the practitioner. Informed decisions should be made by considering such factors as individual clinical expertise and judgement along with patient's circumstances and owners' values. Knowledge Summaries are a resource to help inform and any opinions expressed within the Knowledge Summaries are the author's own and do not necessarily reflect the view of the RCVS Knowledge. Authors are responsible for the accuracy of the content. While the

Editor and Publisher believe that all content herein are in accord with current recommendations and practice at the time of publication, they accept no legal responsibility

for any errors or omissions, and make no warranty, express or implied, with respect to material contained within.

For further information please refer to our Terms of Use.

RCVS Knowledge is the independent charity associated with the Royal College of Veterinary Surgeons (RCVS). Our ambition is to become a global intermediary for evidence based veterinary knowledge by providing access to information

that is of immediate value to practicing veterinary professionals and directly contributes to evidence based clinical decision-making.

\section{https://www.veterinaryevidence.org/}

RCVS Knowledge is a registered Charity No. 230886.

Registered as a Company limited by guarantee in England and Wales No. 598443.

Registered Office: Belgravia House, 62-64 Horseferry Road, London SW1P 2AF

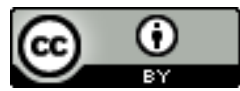

This work is licensed under a Creative Commons Attribution 4.0 International License. 